\title{
Plan de Protección y Salvaguardia del Patrimonio Cultural Arqueológico de Corn Island'
}

\author{
Yamil Serrano Romero \\ BICU-CIDCA
}

\section{INTRODUCCIÓN}

La presente investigación contiene las indicaciones necesarias para hacer efectiva la protección del patrimonio cultural arqueológico de Corn Island, conforme al ordenamiento jurídico existente. Toda gestión de patrimonio histórico y arqueológico se basa en una adecuada labor previa y específica de documentación de los recursos patrimoniales. En este sentido, la Carta Arqueológica es el instrumento que recoge toda la documentación patrimonial existente sobre bienes susceptibles de ser estudiados con metodología arqueológica, y también como herramienta de gestión y de información para garantizar con ello su protección y conservación.

En dicha gestión resulta por consiguiente necesaria la planificación del uso e información que se genera para ejercer un control cuyo fin último es la protección. Por ello, además de la labor propia de la Dirección de Patrimonio del Instituto Nicaragüense de Cultura (INC), la planificación territorial del municipio se erige como uno de los instrumentos que mejor puede garantizar la conservación y salvaguarda preventiva del patrimonio histórico-arqueológico en cualquier tipo de intervención sobre el territorio.

La capacidad de asimilación de los sitios con significación cultural se ha visto considerablemente afectada por las diversas intervenciones humanas. Por tal razón, en la actualidad es indispensable contar con una planificación que contribuya a no sobrepasar su límite. Toda actividad antrópica posee ciertos aspectos de alteración y modificación, los cuales pueden llegar a convertirse en impactos negativos, siendo necesario mitigarlos a través de la integración de acciones protectoras ejecutables a lo largo de todo proceso a desarrollar en un sitio. Según la Carta de Burra, para sitios de significación cultural (1999), “conservación” significa todos los procesos de cuidado de un sitio tendientes a mantener su significación cultural. En este sentido, la conservación del patrimonio cultural puede ser definida en dos niveles diferentes.

El primero involucra el punto de vista físico y lo constituye el conjunto de prácticas o tratamientos específicos destinados a mitigar las alteraciones que perturben los recursos culturales (bienes muebles o inmuebles). El segundo nivel rebasa la acción técnica directa sobre un bien cultural. En este caso, las intervenciones sobre el patrimonio cultural implican el fortalecimiento de los vínculos de la sociedad con su patrimonio. De tal manera que se requiere de la participación activa del ser humano, dueño y creador del patrimonio cultural, como protector consciente del valor que encierran para las futuras generaciones estos sitios arqueológicos.

El artículo 6 de la Carta Internacional para la Gestión del Patrimonio Arqueológico sostiene que: “...el compromiso y la participación de la población local deben impulsarse y fomentarse como medio de promover el mantenimiento del patrimonio arqueológico" (ICOMOS -Internacional Council on Monuments and Sites- 1990).

$1 \quad$ Este plan fue ejecutado en el marco del proyecto investigativo: "Inventario Participativo de 10 Sitios Arqueológicos del territorio indígena Rama y Kriol (Rio Indio) y del territorio afro descendiente de Corn Island, RAAS”, bajo la dirección del Centro de Investigaciones y Documentación de la Costa Atlántica (CIDCA-BICU), con la colaboración de la Asociación por la Naturaleza y la Humanidad con Armonía Trabajo y Libertad (ANAHUATL) y gracias al aporte económico del Fondo Común de Apoyo a la Sociedad Civil para la Gobernabilidad Demócrática en Nicaragua (FGD). 
Con el presente plan se pretende lograr el desarrollo de un proceso de cambio social y la implementación de acciones sostenibles para lograr la conservación de los recursos arqueológicos inventariados en el municipio de Corn Island. Por ello, el plan de salvaguardia y protección del recurso arqueológico se presenta como una estrategia que incluye las opiniones de especialistas en materia de arqueología y los aportes brindados por los actores locales del lugar. Esto, con el objetivo de conservar, manejar y tener un buen aprovechamiento del recurso arqueológico, tomando en cuenta la realidad actual.

Si bien el presente plan se concreta en este documento, su ejecución debe ser, sobre todo, un proceso de trabajo participativo y cotidiano en aspectos sociales y culturales, que deben orientarse en fortalecer la interacción e integración sociocultural del municipio de Corn Island con el recurso arqueológico.

\section{LINIAMIENTOS NORMATIVOS}

En vista de su importancia como elemento manifestador de la identidad cultural e instrumento de desarrollo del pueblo nicaragüense, el Patrimonio Cultural se encuentra protegido por la Constitución Política de la República de Nicaragua. Ésta señala en sus artículos 126 y 128 el deber del Estado de promover el rescate, desarrollo y fortalecimiento de la cultura nacional en todas sus manifestaciones y el de proteger el patrimonio arqueológico, histórico, lingüístico, cultural y artístico de la nación.

El Estado de Nicaragua, a través del Instituto Nicaragüense de Cultura (INC), está a cargo de la protección y conservación de los recursos integrantes del patrimonio cultural de la nación. La protección al Patrimonio Cultural nicaragüense se encuentra garantizada a nivel jurídico por el Decreto 1142 “Ley de Protección al Patrimonio Cultural de la Nación”, publicado en La Gaceta, Diario Oficial, número 282 del dos de diciembre de 1982, que contiene normas de conservación al patrimonio paleontológico, arqueológico, histórico y artístico, a nivel nacional.

Además de la Ley de Protección al Patrimonio Cultural de la Nación, el patrimonio arqueológico está sometido a otro tipo de normativas de rango supranacional, como son: los convenios o convenciones internacionales que nuestro país ha suscrito. Si bien son varias las normas internacionales que pueden aplicarse para nuestro diseño, sin desmerecer las otras, la Carta para la conservación de lugares de valor cultural, más conocida como Carta de Burra, y los documentos anexos a la misma², son los que resultan más apropiados para la problemática que nos atañe. Desde el punto de vista general, la guía para la Carta de Burra recomienda un proceso metódico para medir el valor cultural de un lugar, para preparar una declaración de valor cultural, y para que dicha información reciba difusión pública ${ }^{3}$.

Debido a que el actual marco legal del INC no establece las pautas y lineamientos a seguir para la elaboración de un plan de salvaguardia y protección de sitios arqueológicos, no existe un formato o guía metodológica para su elaboración, por lo cual se debe adecuar en base a otros instrumentos existentes. Este plan que presentamos se ha realizado a partir de lineamientos generales establecidos por normativas creadas en cartas internacionales de protección del patrimonio arqueológico. Para su desarrollo, también fueron consideradas la Ley No. 217 (Ley General del Medio Ambiente y los Recursos Naturales) y las recomendaciones establecidas en el "Reglamento de Investigaciones Arqueológicas” del INC (DECRETO No. 10-2006). Este reglamento establece los procedimientos requeridos para la ejecución de evaluaciones arqueológicas, aunque no contiene una guía para la elaboración de documentos relacionados a un plan de protección y salvaguardia del patrimonio arqueológico.

Debido a este vacío legal, para el presente plan de salvaguardia y protección se complementaron las recomendaciones del Reglamento de Investigaciones Arqueológicas del INC con la “Guía Metodológica para la Elaboración y Actualización de Planes Ambientales Municipales de Nicaragua”, adecuándolos a las características del proyecto.

\section{CARACTERIZACION DE LOS HALLAZGOS ARQUEOLOGICOS}

Debido a la ausencia de estudios arqueológicos sistemáticos en la zona estudiada, todos los sitios arqueológicos deben considerarse importantes desde el punto de vista estrictamente científico y, por lo tanto, deben estimarse las respectivas acciones de investigación y protección. Para el desarrollo del proyecto investigativo de inventario

ICOMS, 1998 ay b

Martínez R, Ismael, s/f. III congreso Chileno de conservación y Restauración. Patrimonio, Conservación y Ciudadanía. 
de sitios arqueológicos en el municipio de Corn Island, ejecutado bajo la dirección del Centro de Investigación y Documentación de la Costa Atlántica (BICU-CIDCA), los sitios arqueológicos identificados fueron clasificados según el tipo de evidencias encontradas: estructuras monticulares, material arqueológico en superficie, petroglifos, áreas de enterramientos, patrones constructivos.

Los resultados de la prospección permitieron localizar en la zona un total de 13 sitios arqueológicos. Cada uno de sus aspectos fue registrado en los diferentes campos descritos en la ficha de registro de sitios arqueológicos, emitida por la dirección de Patrimonio del INC. A éstos se les otorgó un código provisional, se tomó un punto geográfico con GPS para cada hallazgo y se delimitó su área (extensión aproximada); se realizó además la documentación fotográfica de los mismos. En base al análisis de la evidencia tenemos que los sitios fueron clasificados en hallazgos con estructura monticular con material arqueológico cerámico en superficie (3), patrones constructivos (4), sitios con petrograbados (4) y sitios con material arqueológicos en superficie (2). En cuanto al aspecto interpretativo, los sitio Big Bay $\mathrm{N}^{0} 1$ y $\mathrm{N}^{0}$ 3 corresponden a sitios con estructuras monticulares. Destaca el primero, que, a pesar de la fuerte afectación antrópica a que ha estado expuesto, aún presenta características de sitio habitacional por las numerosas evidencias de tiestos cerámico observadas en la superficie del lugar. Sobre él se encuentra construida una vivienda en donde habita una familia que desarrolla su actividad cotidiana sin percatarse de la importancia del lugar en donde están.

Tabla 1. Bienes de interés cultural arqueológico inventariados en el municipio de Corn Island

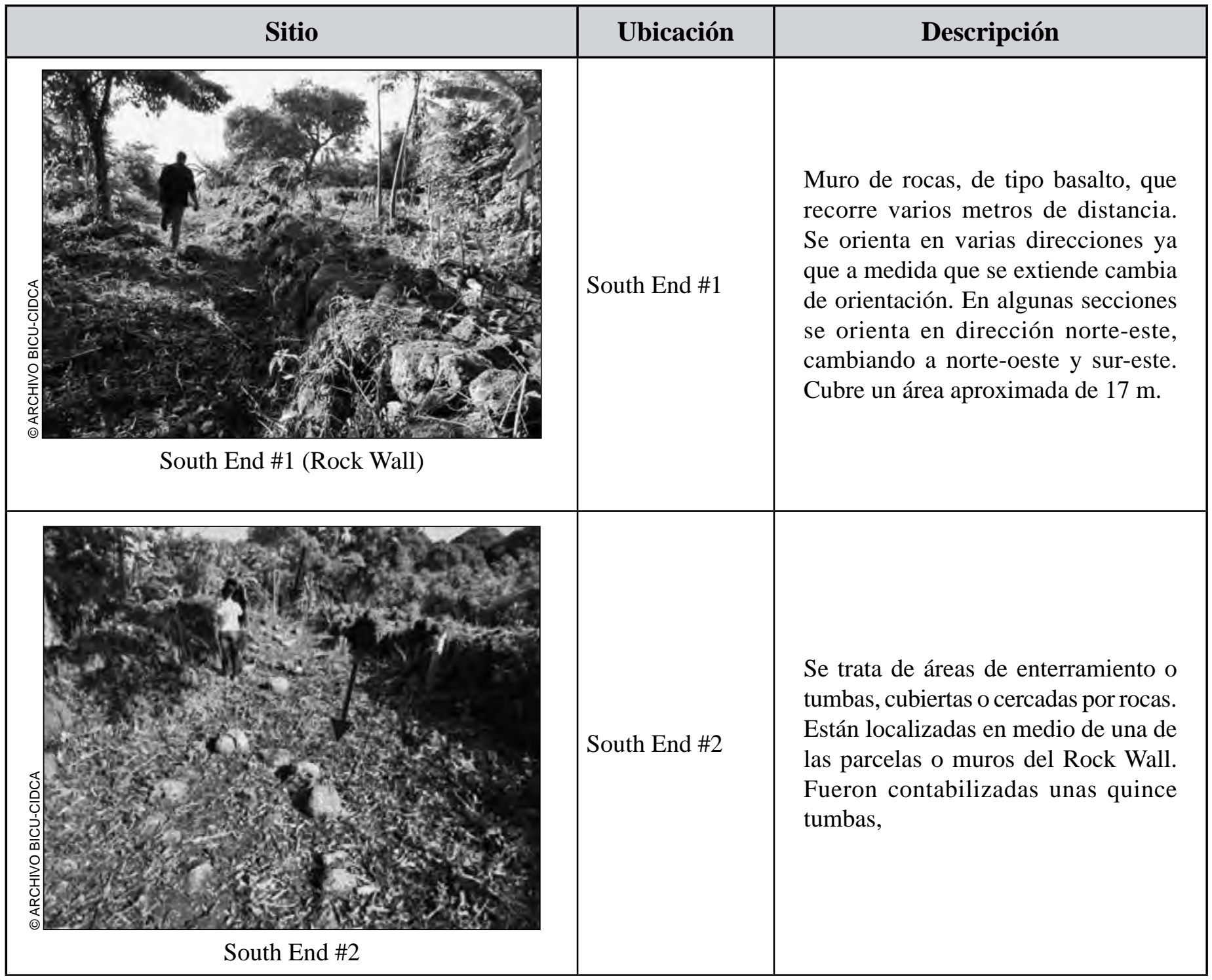




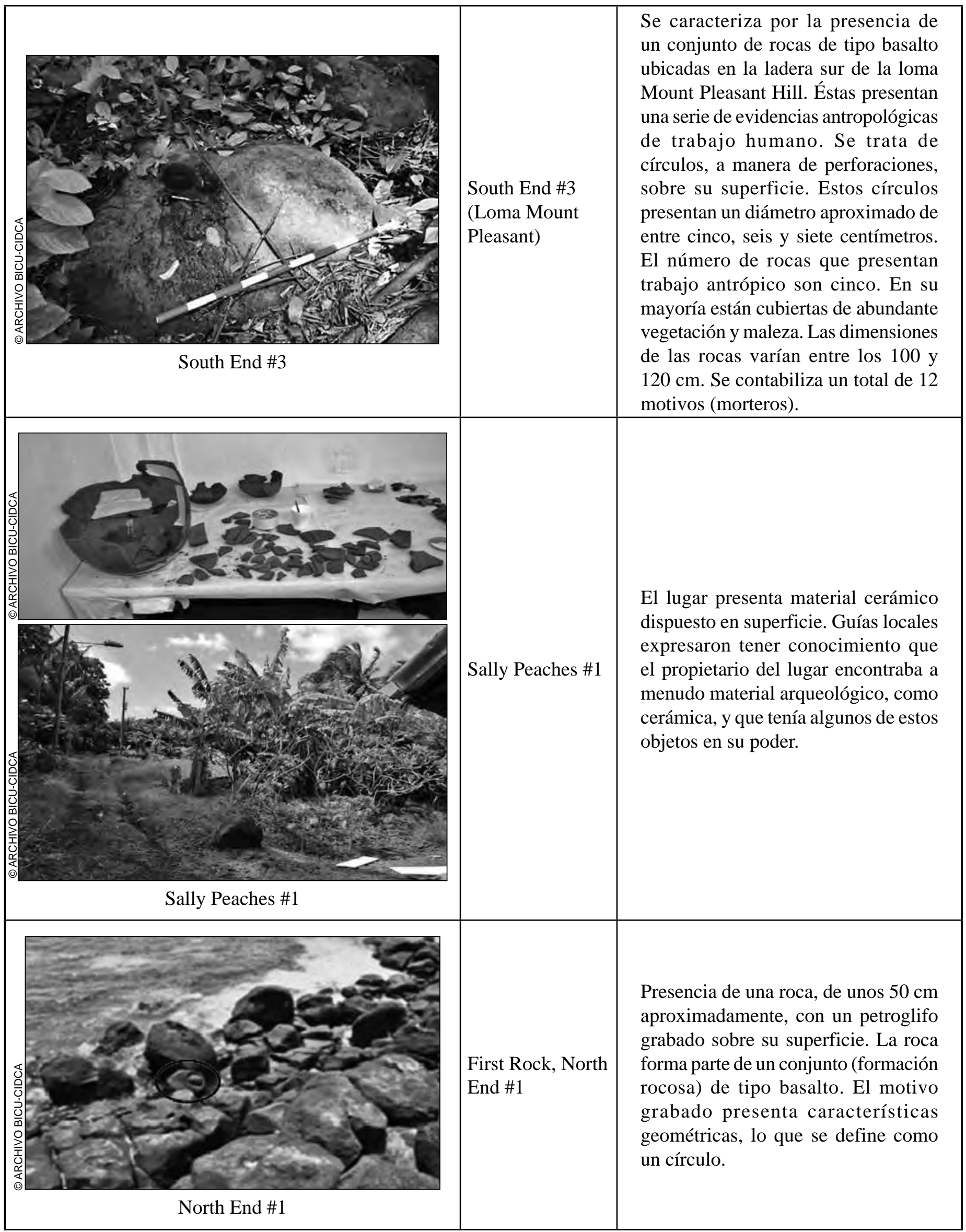




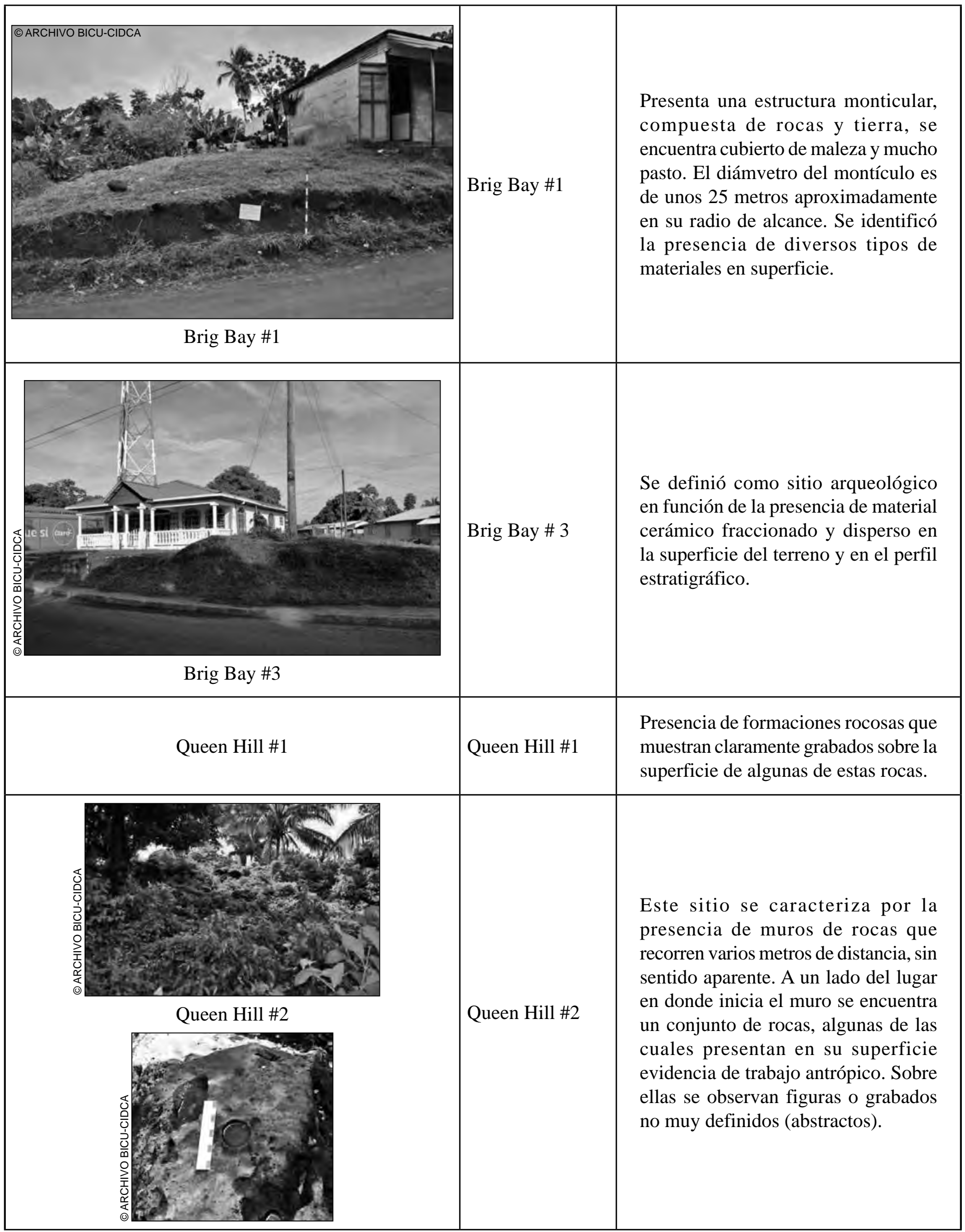




\begin{tabular}{|c|c|c|}
\hline$\varangle$ & South End \#4 & $\begin{array}{l}\text { Se caracteriza por la presencia de } \\
\text { restos de muros de rocas que recorren } \\
\text { varios metros de distancia. Este muro } \\
\text { posee las mismas características } \\
\text { constructivas que el sitio de Rock } \\
\text { Wall, por lo que es muy parecido. }\end{array}$ \\
\hline North End \#2 & North End \# 2 & $\begin{array}{l}\text { Se caracteriza por presentar los restos } \\
\text { de un muro de rocas que forma una } \\
\text { especie de corral (encierro o parcela) } \\
\text { y de material arqueológico dispuesto } \\
\text { en superficie. }\end{array}$ \\
\hline 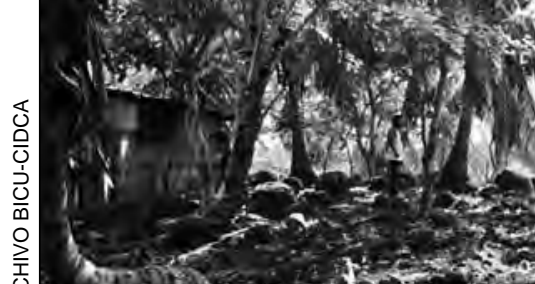 & Queen Hill \# 3 & $\begin{array}{l}\text { Se trata de un montículo compuesto } \\
\text { de rocas y tierra. El lugar se encuentra } \\
\text { emplazado en un área que sirve de } \\
\text { encierro para el ganado, al extremo } \\
\text { noroeste del lugar se encuentra una } \\
\text { vivienda. }\end{array}$ \\
\hline Queen Hill \#3 & & \\
\hline
\end{tabular}

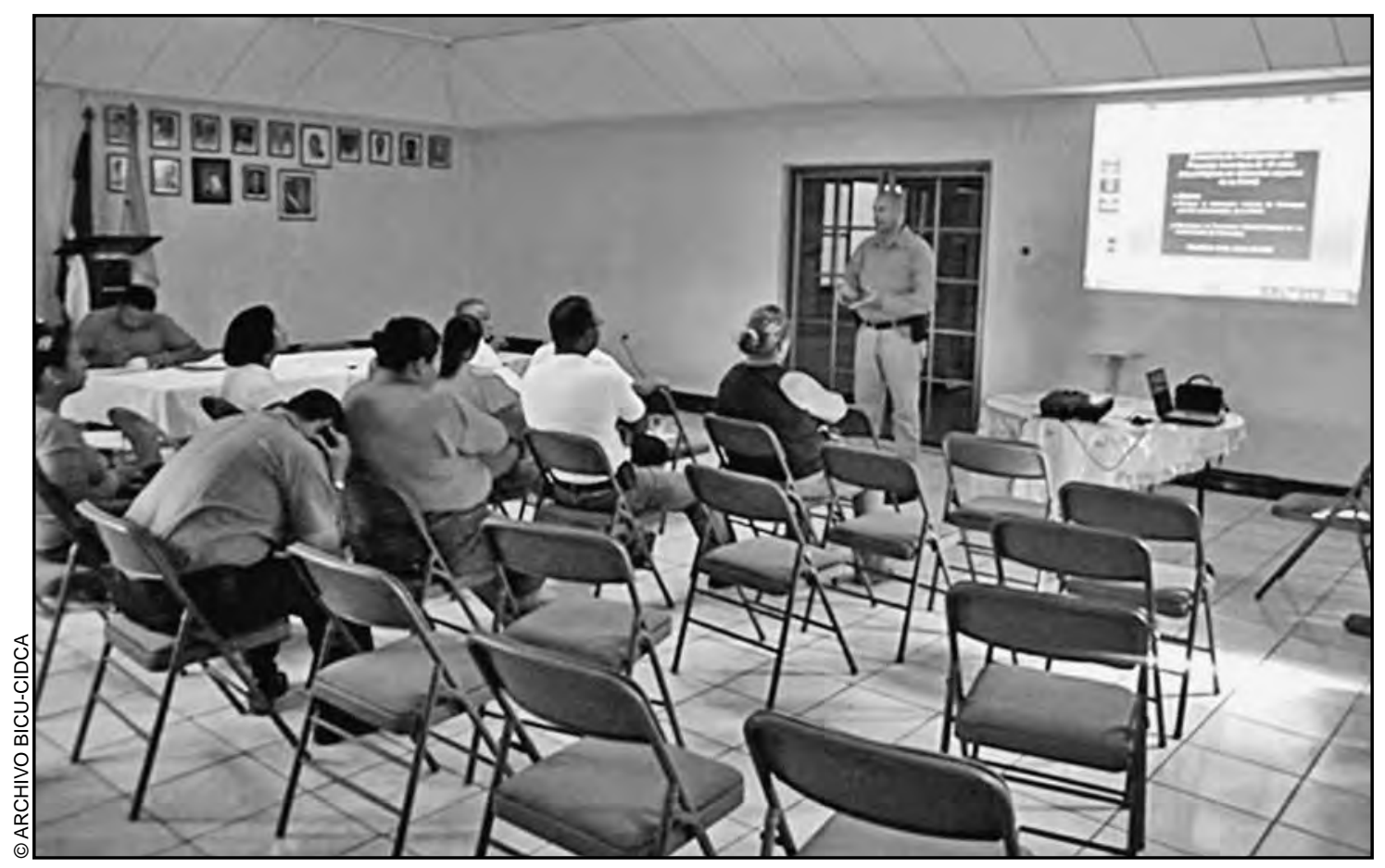

El director de BICU-CIDCA en labores de sensibilización arqueológica en la Isla. Corn Island, 2012. 


\section{Situación Patrimonial de los Sitios}

Las condiciones de conservación y protección de sitios arqueológicos han sido objeto de reflexión, pero en contadas ocasiones han sido propuestas medidas efectivas para ello. Esto obedece en parte a que, en Nicaragua, la orientación de trabajos específicos hacia estos temas es relativamente incipiente. Desde el presente proyecto se viene manejando éste y otros temas vinculados con la gestión del patrimonio arqueológico para este tipo de sitios, en particular, los documentados en la región del Caribe del país.

Los daños más comunes en una zona arqueológica pueden dividirse en dos grupos principales: uno, los que han sido ocasionados por los factores ambientales, y dos, los que se deben a la acción directa o indirecta del ser humano.

Los problemas de protección y conservación que presentan los sitios arqueológicos en el municipio de Corn Island están derivados generalmente de la afección que sufren por el desinterés y desconocimiento acerca de la importancia del patrimonio arqueológico por parte de la población en general. Esto debido a las actividades de ocio o de turismo irresponsable y a los agentes biogénicos y climáticos en general.

En Corn Island, las entidades arqueológicas presentan serios problemas de conservación y protección debido a sus características particulares. Los factores principales y agentes causantes de alteraciones son:

Factores antrópicos: falta de sensibilización, desconocimiento del patrimonio arqueológico, tráfico ilícito, excavaciones arqueológicas ilegales, saqueo o huaquerismo, destrucción de sitios arqueológicos, construcciones humanas, tránsito de vehículos, actividades agropecuarias, propiedad privada.

Factores naturales: dinámica eólica, régimen de lluvias, insolación, acción de agentes biológicos y materia vegetal adherida: raíces, musgos, etcétera. La fuerte incidencia de procesos erosivos naturales, sobre todo la lluvia, el crecimiento y desarrollo de microorganismos (musgo, el moho, etcétera), el crecimiento de las raíces de los árboles, la acumulación de estrato orgánico que, en algunos sitios, deja a los materiales expuestos a la intemperie y a los agentes climáticos o cubiertos de vegetación. La dispersión superficial de materiales es uno de los principales problemas para la conservación ya que algunos sitios arqueológicos, además de estar sometido a los agentes erosivos, quedan totalmente expuestos al expolio arqueológico. Todos estos factores han provocado diferentes grados de afectación para los hallazgos. El grado de alteración que presentan los sitios y los agentes causantes de esa alteración convierten a las zonas arqueológicas en zonas de extrema fragilidad, puesto que resulta muy difícil acometer medidas de conservación efectivas.

A la hora de definir las medidas de protección y conservación para las entidades arqueológicas localizadas en el municipio, es muy importante contemplar el régimen de propiedad del área, ya que cualquier medida establecida debería ser informada y contar con el consenso y aprobación de los propietarios.

\section{CONSIDERACIONES PARA INCORPORAR EN LA PROTECCIÓN DEL PATRIMONIO ARQUEOLOGICO}

El presente plan se propone la protección y salvaguardia del patrimonio arqueológico del municipio de Corn Island. Por protección se entiende todas aquellas actividades que giran en torno al mantenimiento de los bienes arqueológicos y que buscan su estabilización y conservación; abarcan desde estudios de deterioro o intervenciones directas de los vestigios, hasta actividades de sensibilización, educación y valoración que se desarrollen con la comunidad. Considerando lo anterior, la protección y salvaguardia del patrimonio arqueológico se plantea como el conjunto de acciones y/o actividades que giran alrededor de los ejes de conservación, mantenimiento, investigación y educación.

La protección y conservación del patrimonio cultural arqueológico va de la mano con el aumento de la conciencia patrimonial de la población vecina de los sitios donde éstos se encuentran. Esta conciencia patrimonial se logra con trabajo comunitario, con la integración de los actores locales en la toma de decisiones, con la interacción y transferencia de conocimientos entre diferentes organismos y actores involucrados, con educación patrimonial, divulgación y sensibilización de la población en general. En un plan de manejo integral del patrimonio arqueológico se deberían integrar estos aspectos.

\section{Regulaciones Sobre la Protección del Patrimonio Arqueológico}

Estas prescripciones tienen por objeto la conservación y salvaguarda del patrimonio arqueológico, en el ámbito 
municipal de Corn Island. A continuación se desarrollan las prescripciones específicas de protección del patrimonio arqueológico. Culminada ya la fase inicial de documentación e inventario de sitios arqueológicos se deberá incorporar, o desarrollar, un plan específico de gestión para el patrimonio arqueológico del municipio. A continuación avanzamos en algunas de las medidas establecidas en los diferentes ámbitos que deberá abordar el futuro plan. Dicho plan deberá incluir las medidas básicas para la gestión, protección y conservación del patrimonio cultural arqueológico.

Integran el patrimonio histórico-arqueológico del municipio de Corn Island, para efectos de su protección específica, los bienes de interés cultural incluidos en el Inventario de sitios arqueológicos, desarrollado con el proyecto de inventario de sitios ejecutado por el Centro de Investigación y Documentación de la Costa Atlántica (BICU-CIDCA). Los bienes de interés cultural son la máxima figura de protección jurídica, y protección singular, expresada en el Arto. $1^{\circ}$ del Decreto No 1142: Ley de Protección al Patrimonio Cultural, publicado en la Gaceta, Diario Oficial, No 282 del dos de diciembre de 1982.

\section{Definición de Categorías de Sitios}

Para el municipio de Corn Island, las entidades arqueológicas se presentan como áreas de diferente tamaño y morfología; una vez hecha la valoración arqueológica vemos que, en realidad, se trata de una distribución de puntos que se ubican en diferentes lugares de la Isla Grande del Maíz: en zonas altas, zonas costeras y zonas intermedias.

Como de lo que se trata es de preservar, además de los sitios arqueológicos en sí mismo, el contexto y entramado de relaciones que se establecen con otros elementos del entorno, lo más apropiado, en este caso, es definir de momento ámbitos de protección y de prevención arqueológica. Según lo definido en el Decreto No 1142 Ley de Protección al Patrimonio Cultural, estos ámbitos son:

\section{Ámbitos arqueológicos de protección. Son los lugares o áreas con existencia probada de sitios arqueológicos, de valor relevante. Se incluyen en ellos aquellos que figuren identificados en el Inventario de bienes inmuebles.}

\section{Ámbitos arqueológicos de prevención.}

Son los lugares o áreas que tienen probada la existencia de restos arqueológicos o en los cuales existe presunción razonada y probable de aparición de los mismos.

La ausencia de estudios arqueológicos sistemáticos en el municipio, y la consideración de que algunos de estos sitios identificados tienen potenciales atributos arqueológicos -a pesar de las diferencias en cuanto a cantidades y tipos de evidencias-, robustecen la posibilidad de aportar datos que ayuden a comprender las sociedades pasadas. Se debe priorizar una categorización para cada sitio; los ámbitos arqueológicos de protección y de prevención, que han de definirse para el término municipal de Corn Island, convendrían ser realizados teniendo en cuenta, e incluyendo en ellos, la realidad, el potencial arqueológico y la singularidad de los ámbitos. Deben establecerse sobre la base de los tipos y artefactos de cada sitio determinado. Desde el punto de vista estrictamente científico, todos los sitios arqueológicos se consideran importantes y por lo tanto deben estimarse las respectivas acciones de investigación, protección y mitigación. Dichos ámbitos deberán ser regulados a través de cuantas disposiciones legales se puedan establecer; por ejemplo, un plan de ordenanza municipal para declarar la existencia de zonas o áreas arqueológicas.

Para el presente plan, los sitios arqueológicos identificados deben ser clasificados según su importancia. Esta clasificación estará basada en el reconocimiento de la superficie, ubicación del sitio con relación a las áreas pobladas, tipo de sitios (entierros, estructuras monticulares, etcétera), complejidad de los materiales, extensión superficial, etcétera. Además de complementar los datos con la realización de estudios complementarios, excavaciones, documentación de sitios, etcétera.

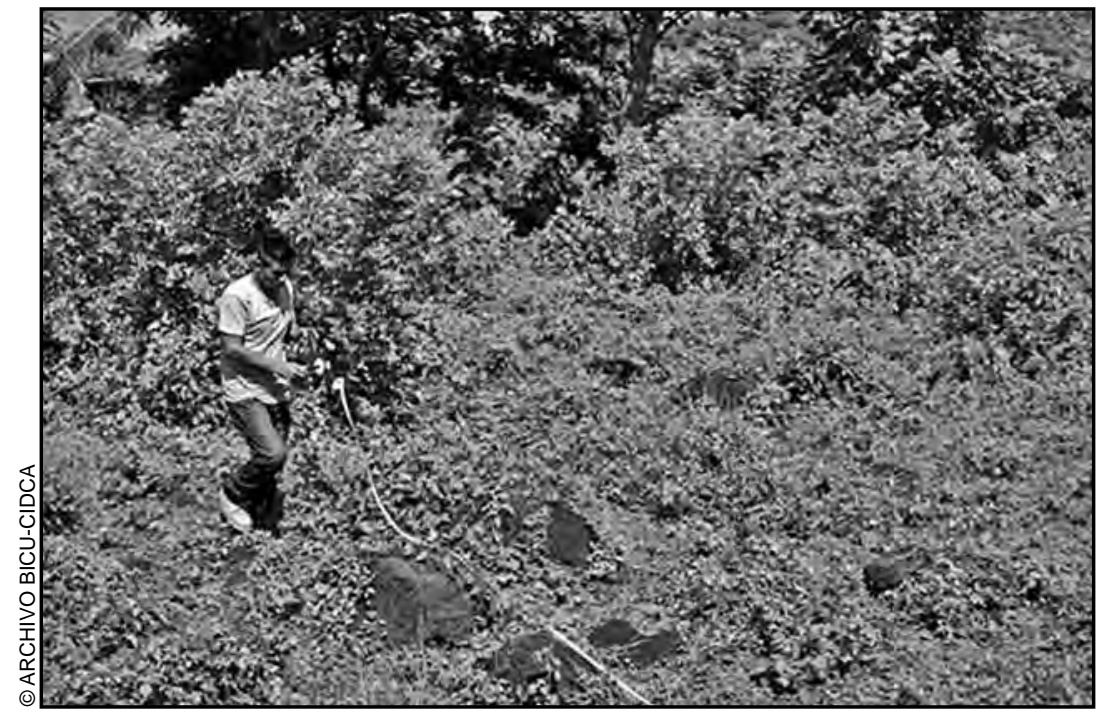

Integrante del equipo ejecutor del proyecto tomando medidas. Corn Island, 2012. 
Cuando se haya procedido a la declaración de una zona o aérea arqueológica, como bien de interés cultural, será obligatorio que el municipio redacte un plan Especial de Protección del área afectada por la declaración, u otro instrumento de planeamiento de los previstos en la legislación urbanística, que cumpla con las exigencias establecidas por la Ley de Protección al Patrimonio Cultural. Asimismo, y recogiendo lo dispuesto en los convenios internacionales para la protección del patrimonio arqueológico se deberá “delimitar y proteger los lugares y conjuntos de interés arqueológico y constituir zonas de reserva para la conservación de testimonios materiales”.

\section{Planes y Programas en Ámbitos Arqueológicos de Protección y Prevención}

1. Previo a la autorización municipal de cualquier plan o programa urbanístico deberá existir una resolución de la
Dirección de Patrimonio sobre la incidencia, compatibilidad y viabilidad de dichos planes o programas, en relación al patrimonio histórico-arqueológico. Dicha resolución se realizaría a la vista de una propuesta razonada por un técnico cualificado y presentada por parte de la promotora o propiedad de dichos planes o programas, para su debida integración, conservación, propuesta de valoración y medidas correctoras previas a cualquier intervención.

2. Los planes y programas urbanísticos deberán contemplar la conservación de aquellos elementos del patrimonio histórico-arqueológico identificados en el presente proyecto de inventario de sitios arqueológicos.

3. En cuanto a los sitios arqueológicos identificados en el proyecto se tendería a la conservación de sus características estructurales y estéticas, siendo necesaria para su alteración una declaración específica por parte de la Dirección de Patrimonio del INC.

Medidas para la Conservación y Prevención de Afectaciones

Tabla 2. Actividades de prevención, mitigación, mantenimiento y conservación para los sitios

\begin{tabular}{|c|c|c|}
\hline Sitio & Ubicación & Actividad de prevención, mitigación, mantenimiento y conservación \\
\hline $\begin{array}{l}\text { South End \#1 } \\
\text { (Rock Wall) } \\
\text { South End \#2 } \\
\text { South End \#3 } \\
\text { South End \#4 }\end{array}$ & South End & 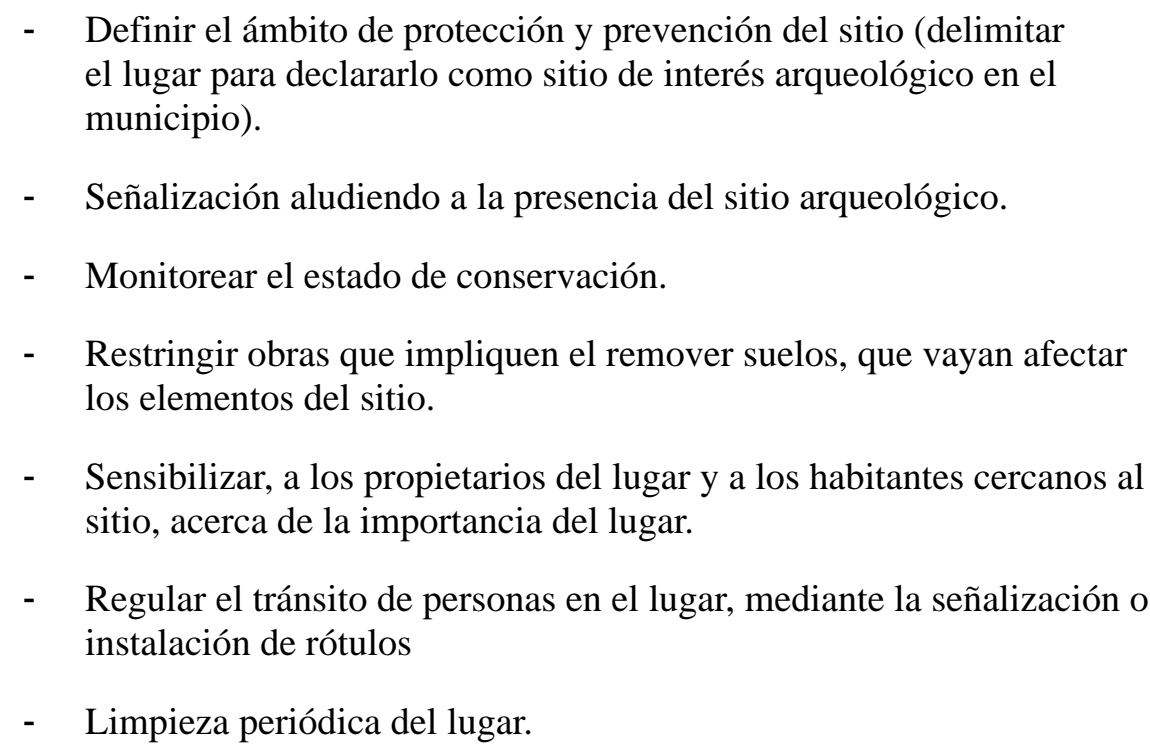 \\
\hline
\end{tabular}




\begin{tabular}{|c|c|c|}
\hline Sally Peaches \#1 & Sally Peaches & 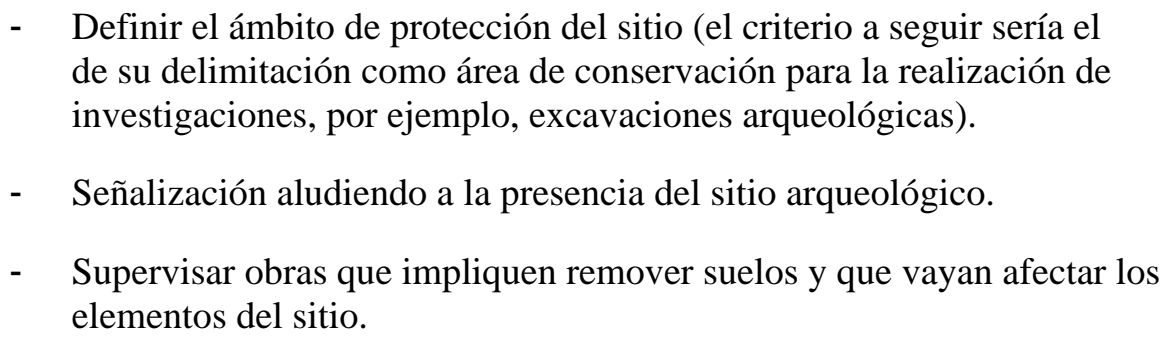 \\
\hline $\begin{array}{l}\text { North End \#1 } \\
\text { North End \#2 }\end{array}$ & North End & $\begin{array}{l}\text { - } \begin{array}{l}\text { Definir el ámbito de protección y prevención para los sitios (por } \\
\text { ejemplo delimitar el área del sitio North End \#1, para declararlo como } \\
\text { sitio de interés arqueológico) }\end{array} \\
\text { - } \quad \text { Señalización aludiendo a la presencia del sitio arqueológico. } \\
\text { - } \quad \text { Monitorear el estado de conservación. } \\
\text { - Sensibilizar a los habitantes cercanos a los sitios acerca de la } \\
\text { importancia del lugar. }\end{array}$ \\
\hline $\begin{array}{l}\text { Brig Bay \#1 } \\
\text { Brig Bay \#3 }\end{array}$ & Brig Bay & 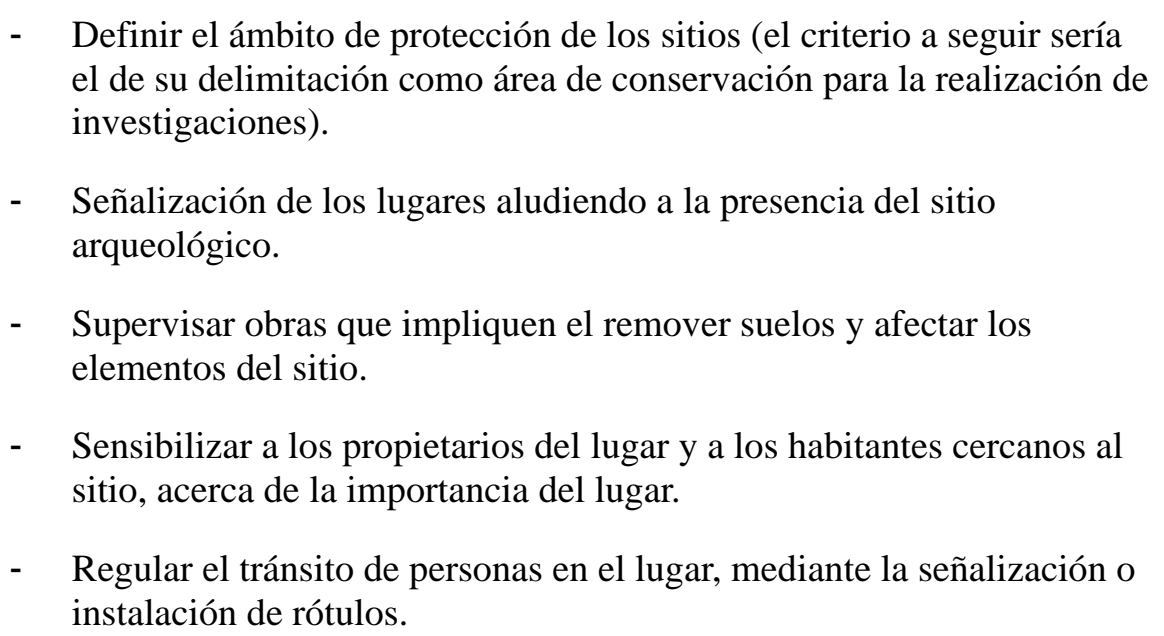 \\
\hline $\begin{array}{l}\text { Queen Hill \#1 } \\
\text { Queen Hill \#2 } \\
\text { Queen Hill \#3 }\end{array}$ & Queen Hill & $\begin{array}{l}\text { - } \begin{array}{l}\text { Definir el ámbito de protección y prevención del sitio (delimitar } \\
\text { el lugar para declararlo como sitio de interés arqueológico en el } \\
\text { municipio). }\end{array} \\
\text { - } \quad \text { Señalización aludiendo la presencia del sitio arqueológico. } \\
\text { - } \quad \text { Monitorear el estado de conservación. } \\
\text { - } \quad \text { Restringir obras que impliquen el remover suelos, que vayan afectar } \\
\text { los elementos del sitio. } \\
\text { - } \quad \begin{array}{l}\text { Sensibilizar a los propietarios del lugar y a los habitantes cercanos al } \\
\text { sitio, acerca de la importancia del lugar. }\end{array} \\
\text { - } \quad \text { Regular el tránsito de personas en el lugar, mediante la señalización o } \\
\text { instalación de rótulos. }\end{array}$ \\
\hline
\end{tabular}




\section{Medidas para el Fomento de la Investigación}

Dentro de las medidas para impulsar la investigación científica en el área proponemos establecer un memorando de colaboración entre diferentes organismos y profesionales que trabajan la temática arqueológica, de tal manera que se desarrollen los mecanismos para:

- Estimular el desarrollo de proyectos interdisciplinares en los cuales tengan cabida la investigación de distintos aspectos y que favorezcan la transferencia de conocimientos entre los diferentes campos de conocimiento.

- Impulsar proyectos de investigación para resolver las demandas de la gestión.

- Favorecer el perfeccionamiento y la especialización de técnicos autóctonos que ayuden a la comunidad en el mantenimiento del recurso arqueológico.

\section{Puesta en Valor y Socialización}

En este proyecto, no hemos acometido el diseño de un programa de divulgación y socialización del patrimonio arqueológico. Un programa de puesta en valor forma parte, además, de un plan de manejo del patrimonio integral o arqueológico, con lo cual, esta tarea deberá ser realizada de forma conjunta, para asegurar la visión integral del área y su patrimonio arqueológico y para exponer todos sus valores, promoviendo la conservación y protección del paisaje cultural. No obstante, desde el proyecto, y como primer paso, fueron desarrolladas dos tareas concretas: el diseño de un programa de capacitación en temas de patrimonio cultural, que fue dirigido e impartido, en particular, a líderes indígenas y afro descendiente, autoridades comunales, municipales y regionales, y la divulgación, por medio de presentaciones visuales, sobre los resultados de la realización del inventario.

Dentro del programa de puesta en valor deberán integrarse diferentes actuaciones orientadas a la socialización del patrimonio arqueológico. El campo de puesta en valor y socialización cuenta con una amplia gama de herramientas para llegar a todo tipo de público, algunas de las cuales consideramos apropiadas para ser integradas en el futuro plan de gestión de sitios arqueológicos. Para esto planteamos:

Programa de divulgación del valor patrimonial a la sociedad en su conjunto, en donde se ponga el énfasis en la necesidad de conservación y protección del paisaje arqueológico, a través de diferentes medios de comunicación masiva: audiovisual, prensa local o nacional, folletos en puntos de información turísticas, página Web.
Programa de educación patrimonial: diseño de charlas, talleres y unidades didácticas para escuelas y para centros de divulgación del patrimonio, como pueden ser, casa comunal, alcaldía de Corn Island, etcétera. Sería interesante combinarlo con las actividades de educación ambiental. Los aspectos de capacitación arqueológica deberán comprender los temas de legislación sobre patrimonio cultural, aspectos sociales, arqueológicos y culturales, áreas altamente sensibles desde el punto de vista arqueológico, conservación y protección del patrimonio arqueológico entre otros.

Actividades de interpretación del patrimonio arqueológico: constituido por un plan de actividades orientadas a niños, turistas, población local. Estas actividades tendrán como objetivo el reconocimiento e interpretación de los valores culturales del área desde la perspectiva de la Arqueología del Paisaje.

Se pueden incluir, a modo de ejemplo, actividades como: visitas guiadas a los sitios arqueológicos, talleres de actividades, participación en celebraciones colectivas con motivos arqueológicos.

Diseño de iniciativas de puesta en valor de bajo impacto o planteadas para el desarrollo de un turismo responsable, por ejemplo: diseño de rutas de interpretación arqueológica dentro del área, con contenidos derivados de las investigaciones científicas, que se desarrollen y que apuesten por la interpretación de los sitios y el reconocimiento de su valor patrimonial.

Señalización en las áreas arqueológicas que proporcione información a los paseantes, sobre los valores arqueológicos del área, que provea herramientas para interpretar arqueológicamente el área y que al mismo tiempo enfatice la necesidad de proteger, conservar y no expoliar los sitios arqueológicos. Esta señalización se recomienda que sea una señalización del conjunto, y geográficamente relativa. Asegurándonos de indicar la presencia de sitios arqueológicos (por ej. señalización del toda la loma como área arqueológica), pero que tampoco facilite o promueva la destrucción y expolio de los sitios.

\section{SEGUIMIENTO Y EVALUACIÓN DE LA EJECUCIÓN DEL PLAN}

La ejecución de las acciones del Plan está en función de las medidas de mitigación y prevención para el recurso arqueológico, respondiendo a las prioridades de inversión 
identificadas. Su estrategia de implementación contempla la participación de todos los actores locales, con el fin de reorientar la gestión del patrimonio arqueológico en el municipio. Esta articulación inicia con la aprobación del plan a través de las autoridades municipales, mediante instrumentos jurídicos que sean pertinentes para que de esta manera se gestione, en conjunto con los actores locales, los recursos financieros y humanos necesarios para garantizar su ejecución.

El fortalecimiento de las autoridades municipales y los actores locales, como garantes del seguimiento en la implementación del plan, así como el proceso de sensibilización de todos los sectores del municipio a través de su divulgación, plantea una valoración numérica sobre el estado actual de los ámbitos arqueológicos de protección y prevención arqueológica en el municipio, considerándose como la línea base en la ejecución de este primer plan.

\section{Evaluación y Monitoreo}

Uno de los problemas más comunes en todo proceso de planificación es, precisamente, la falta de mecanismos de evaluación que permitan establecer tanto el grado de aplicación que ha tenido un plan, como el grado de impacto y cumplimiento de los objetivos alcanzados. Este plan se propone la construcción de matrices de evaluación y monitoreo, que reflejen, las principales variables a evaluar obtenidos de las principales propuestas. El plan de salvaguardia y protección del patrimonio cultural para los sitios arqueológicos orienta la ejecución de acciones necesarias a través de la implementación de las líneas estratégicas. Esto tiene como objetivo el mejoramiento de la calidad de vida de los habitantes del municipio, a través de la protección de los recursos arqueológicos. Sin embargo, estas orientaciones estratégicas demandan su validación sistemática a fin de evaluar el nivel de complimiento e impacto real del mismo. De esta manera se dinamiza la ejecución para lograr los impactos planteados o replantear las estrategias convencionales.

Tabla 3. Matriz de evaluación y seguimiento del Plan

\begin{tabular}{|c|c|c|c|c|}
\hline Acción E y M & ¿Qué? & ¿Quien? & ¿Cuando? & Instrumento \\
\hline $\begin{array}{l}\text { Monitoreo a la } \\
\text { implementación del Plan. }\end{array}$ & $\begin{array}{l}\text { Inclusión del Plan a } \\
\text { POAs. } \\
\text { Alcance de resultados } \\
\text { esperados (talleres, } \\
\text { perfiles de proyectos, } \\
\text { movilización de fondos). }\end{array}$ & $\begin{array}{l}\text { Alcaldía municipal, } \\
\text { actores locales } \\
\text { con proyectos } \\
\text { específicos, } \\
\text { Ejército, Policía } \\
\text { etcétera. }\end{array}$ & $\begin{array}{l}\text { Todo el } \\
\text { periodo. }\end{array}$ & $\begin{array}{l}\text { POAs, cartera de } \\
\text { proyectos culturales } \\
\text { arqueológicos } \\
\text { específicos. }\end{array}$ \\
\hline $\begin{array}{l}\text { Evaluación del desarrollo } \\
\text { de capacidades } \\
\text { municipales en gestión del } \\
\text { patrimonio arqueológico. }\end{array}$ & $\begin{array}{l}\text { Comparación con la } \\
\text { situación anterior. }\end{array}$ & $\begin{array}{l}\text { Concejo Municipal, } \\
\text { actores locales. }\end{array}$ & Anualmente. & $\begin{array}{l}\text { Guía de autoevaluación } \\
\text { y la ejecución del plan. }\end{array}$ \\
\hline $\begin{array}{l}\text { Evaluación del alcance de } \\
\text { las metas. }\end{array}$ & $\begin{array}{l}\text { Analizar si el contexto } \\
\text { del patrimonio cultural } \\
\text { arqueológico está } \\
\text { mejorando o no. }\end{array}$ & $\begin{array}{l}\text { CIDCA-BICU, } \\
\text { Concejo Municipal, } \\
\text { actores locales }\end{array}$ & Semestral. & $\begin{array}{l}\text { Información de } \\
\text { proyectos propuestos } \\
\text { con el plan. }\end{array}$ \\
\hline Divulgación del plan. & $\begin{array}{l}\text { Conocimiento del } \\
\text { contenido del plan por } \\
\text { parte de la población. }\end{array}$ & $\begin{array}{l}\text { Alcaldía, CIDCA- } \\
\text { BICU, actores } \\
\text { locales, Ejército, } \\
\text { Policía, etcétera. }\end{array}$ & Semestral. & $\begin{array}{l}\text { Ordenanzas, } \\
\text { audiovisuales (radio, } \\
\text { televisión, prensa escrita, } \\
\text { otros). }\end{array}$ \\
\hline
\end{tabular}




\begin{tabular}{|l|l|l|l|l|}
\hline Sensibilización. & $\begin{array}{l}\text { Charlas del patrimonio } \\
\text { a niños, y jóvenes en } \\
\text { colegios y la comunidad, } \\
\text { creación de brigadas, } \\
\text { etcétera. }\end{array}$ & $\begin{array}{l}\text { CIDCA-BICU } \\
\text { Alcaldía }\end{array}$ & Bimensual. & Guías, manuales. \\
\hline $\begin{array}{l}\text { Preservación de zonas } \\
\text { arqueológicas. }\end{array}$ & $\begin{array}{l}\text { Investigaciones y } \\
\text { estudios arqueológicos. }\end{array}$ & $\begin{array}{l}\text { Investigadores del } \\
\text { país. }\end{array}$ & $\begin{array}{l}\text { Todo el } \\
\text { periodo. }\end{array}$ & $\begin{array}{l}\text { Reglamentos en la } \\
\text { materia. }\end{array}$ \\
\hline $\begin{array}{l}\text { Rescate del patrimonio } \\
\text { arqueológico. }\end{array}$ & $\begin{array}{l}\text { Preservación e } \\
\text { inventario de objetos } \\
\text { arqueológicos existentes } \\
\text { en el municipio: museos, } \\
\text { exhibiciones itinerantes, } \\
\text { etcétera. }\end{array}$ & $\begin{array}{l}\text { CIDCA-BICU, } \\
\text { Alcaldía, actores } \\
\text { locales, Ejército, } \\
\text { Policía, etcétera. }\end{array}$ & $\begin{array}{l}\text { Todo el } \\
\text { periodo. }\end{array}$ & $\begin{array}{l}\text { Objetos, museos, } \\
\text { fotografías, }\end{array}$ \\
\hline $\begin{array}{l}\text { Coordinación institucional } \\
\text { y CIDCA-BICU. }\end{array}$ & $\begin{array}{l}\text { Inspección/supervisión } \\
\text { de los sitios y proyectos. }\end{array}$ & $\begin{array}{l}\text { CIDCA-BICU, } \\
\text { otras instituciones. }\end{array}$ & Semestral. & Bitácoras de procesos. \\
\hline
\end{tabular}

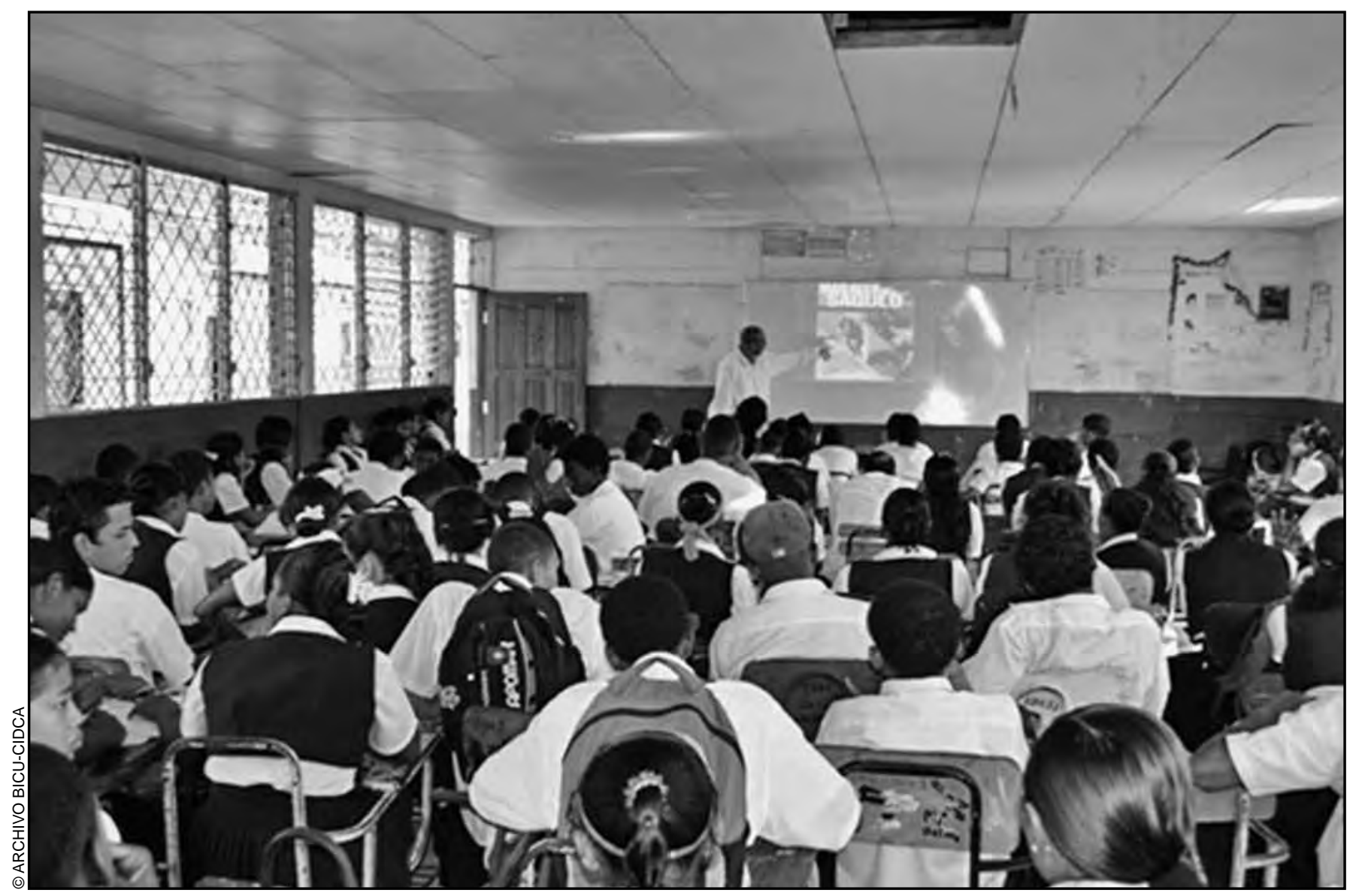

El director de BICU-CIDCA en labores de sensibilización arqueológica en la Isla. Corn Island, 2012. 


\section{BIBLIOGRAFIA}

Balladares S. y Lechado L. 2012. Exploración Arqueológica en Territorio Indígena Rama - Kriol Informe Técnico. UNAN, MANAGUA, Facultad de Humanidades y Ciencias Jurídicas, Depto. de Historia.

Ballart Joseph. 1997. El patrimonio Histórico y Arqueológico. Valor y uso. Editorial Ariel, S.A. Barcelona España. 268 pág. Carta de Venecia-ICOMOS. 1965. CARTA INTERNACIONAL SOBRE LA CONSERVACIÓN Y LA RESTAURACIÓN DE MONUMENTOS Y DE CONJUNTOS HISTÓRICO-ARTÍSTICOS

Carta ICOMOS. 2008. Para Interpretación y Presentación de Sitios de P. C.

Concepción de María. FUNDAR, con el auspicio del Proyecto Gestión Ambiental Amigos de la Tierra/España - Cooperación Española Managua, Nicaragua. 181 pp.

Convención de la Haya. 1954. Convención para la protección de los bienes culturales en caso de conflicto armado.

Convención de París. 1970. Convención sobre la Protección del Patrimonio Mundial Cultural y Natural.

Convención de París. 1972. Convención sobre la protección del P. mundial, cultural y natural.

Convención de San Salvador, 1976. CONVENCION SOBRE DEFENSA DEL PATRIMONIO ARQUEOLOGICO, HISTORICO Y ARTISTICO DE LAS NACIONES AMERICANAS

Fernández Arena José. 1996. Introducción a la conservación del patrimonio y técnicas artísticas. Editorial Ariel S.A. España. 177 pág.

Fonseca, O y Cooke, R. 1993. “El sur de América Central: contribución al estudio de la región histórica Chibcha”. Historia General de C.A. T. I, Cap. 4. Edición R. Carmack.

Gobierno de Nicaragua. 1990. Decreto ejecutivo No. 527. Áreas protegidas del Sureste de Nicaragua. Publicado en la Gaceta, Diario oficial \# 78 del 17 de Abril de 1990. Managua, Nicaragua.

Gobierno de Nicaragua. 1994. Decreto 28-94. Declaración de la región del Sureste de Nicaragua, territorio de desarrollo sostenible. La Gaceta, Diario oficial \# 106 del miércoles 8 de Junio de 1994. Managua, Nicaragua.

Gobierno de Nicaragua. 1996. Ley General del Medio Ambiente y de los Recursos Naturales, artos. 38, 39, 41 y 42 . Publicado en FUNDENIC 2003. Managua, Nicaragua. 117 pp.

GTR-K. 2009. Plan Autónomo de Desarrollo y Administración del Territorio Rama y Kriol (PADA) primera versión actualizada.

ICOMOS, 1990. Carta Internacional para la gestión del patrimonio arqueológico

ICOMOS, 2009. News Letter. Edición especial.

ICOMOS. 2008. Carta de Itinerarios Culturales. Canadá.

MARENA. 2003. Plan de Manejo del Monumento Histórico Fortaleza de la Inmaculada

Querol, M. A y Martínez, B. 1996. La Gestión del Patrimonio Arqueológico en España. Alianza Editorial. Madrid, España.

Querol, M. A. 1998. Legislación Internacional sobre Patrimonio Arqueológico. Seminario. UNAN - Managua.

Serrano R. Y. 2013. Informe Prospección Arqueológica. Proyecto: "Inventario Participativo de 10 Sitios Arqueológicos del Territorio Indígena Rama-Kriol y del Territorio Afro descendiente de Corn Island RAAS”. CIDCA-BICU.

Squier E. G: 1860. Nicaragua sus gentes y paisajes. Editorial Universitaria Centroamericana (EDUCA).

UNESCO. 1956. Conferencia general. 
ANEXO

MAPA Y FIGURAS

Figura 1. Ubicación de sitios arqueológicos inventariados en el proyecto de inventario de sitios arqueológicos, en el proyecto BICU-CIDCA

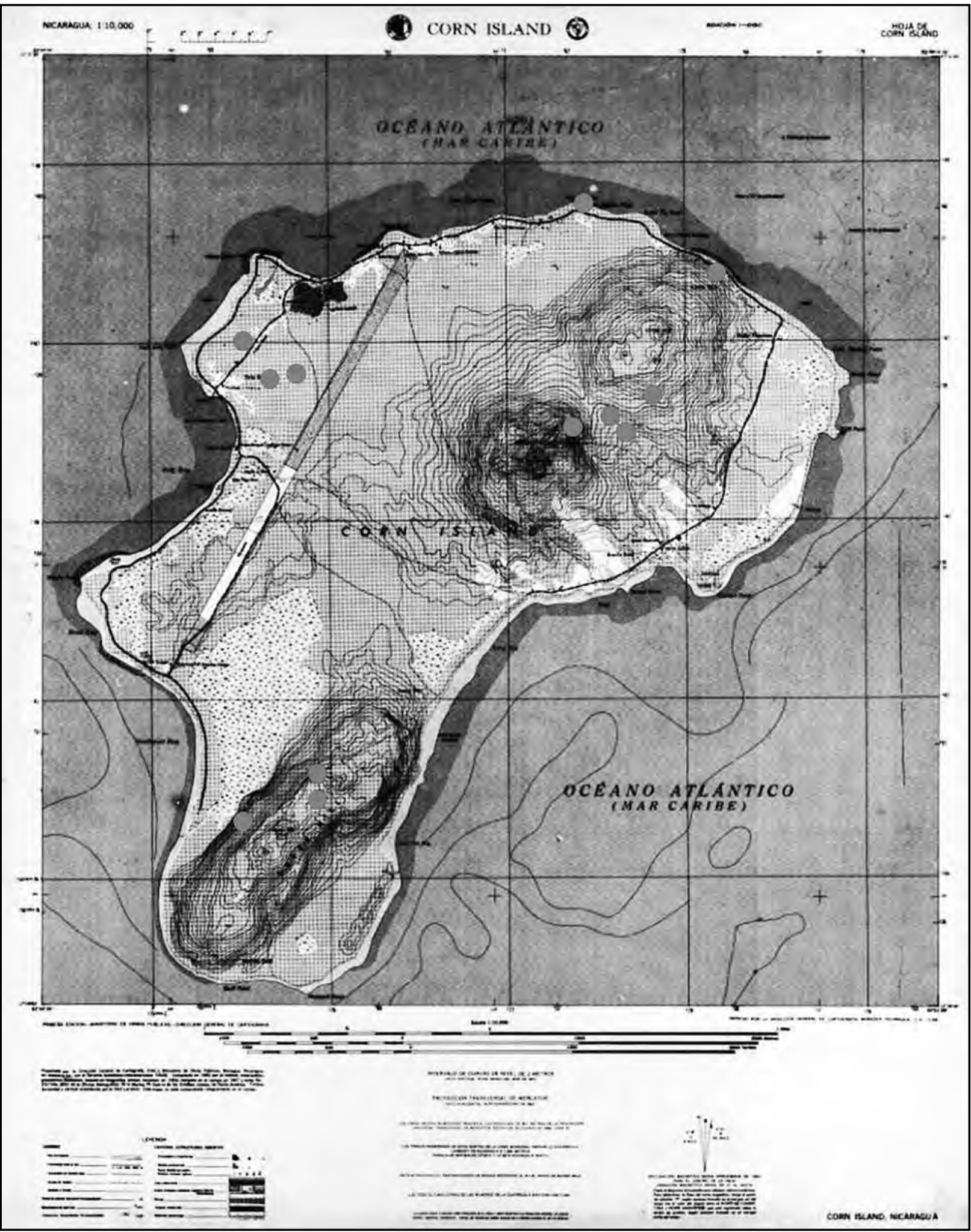

